\title{
Karakteristik Pulp Hasil Pemutihan Dari Tandan Kosong Kelapa Sawit Hasil Pemasakan Yang Menggunakan Limbah Lindi Hitam Siklus Ketiga
}

\author{
Sri Hidayati, Ribut Sugiharto, Ahmad Sapta Zuidar \\ Jurusan Teknologi Hasil Pertanian, Fakultas Pertanian, Universitas Lampung, Bandar lampung \\ *email korespondensi: srihidayati.unila@gmail.com
}

\begin{abstract}
Oil Palm Empty Bunches (OPEFB) are agroindustrial wastes that contain cellulose so that they can be used as raw material for pulping. The process of pulping from formacell OPEFB produces pulp with a dark color that requires a bleaching or bleaching process. The purpose of this study was to determine the effect of bleaching time using $\mathrm{H}_{2} \mathrm{O}_{2}$ with a concentration of $35 \%$ in acetic acid media on the characteristics of pulp from OPEFB which was cooked using the formacell process. The bleaching time used was $0.5,1,1.5,2$ and 2.5 hours using $800 \mathrm{C}$ cooking temperature. The study was repeated 3 times. The results showed that the best treatment occurred at the bleaching time for 2 hours which produced a yield of $79.6 \%$, cellulose $51.08 \%$, permanganate number 6.8 and the score for color was 4.5 (white).
\end{abstract}

Keywords: bleaching, formacell, $\mathrm{H}_{2} \mathrm{O}_{2}, \mathrm{OPEFB}$

\begin{abstract}
Abstrak. Tandan Kosong Kelapa Sawit (TKKS) merupakan limbah agroindustri yang mengandung selulosa sehingga dapat dimanfaatkan sebagai bahan baku pembuatan pulp. Proses pembuatan pulp dari TKKS secara formacell menghasilkan pulp dengan warna yang masih gelap sehingga memerlukan proses bleaching atau pemutihan. Tujuan penelitian ini adalah mengetahui pengaruh lama waktu pemutihan dengan menggunakan $\mathrm{H}_{2} \mathrm{O}_{2}$ dengan konsentrasi $35 \%$ dalam media asam asetat terhadap karakteristik pulp dari TKKS yang dimasak menggunakan proses formacell. Lama waktu pemutihan yang digunakan adalah 0,5, 1, 1,5, 2 dan 2,5 jam dengan menggunakan suhu pemasakan $80^{\circ} \mathrm{C}$. Penelitian diulang sebanyak 3 kali. Hasil penelitian menunjukkan bahwa perlakuan yang terbaik terjadi pada lama pemutihan selama 2 jam yang menghasilkan rendemen sebesar $79,6 \%$, selulosa $51,08 \%$, bilangan permanganat 6,8 dan skor terhadap warna adalah 4,5 (putih).
\end{abstract}

Kata Kunci: formacell, $\mathrm{H}_{2} \mathrm{O}_{2}$, pemutihan, TKKS

\section{Pendahuluan}

Tandan kosong kelapa sawit (TKKS) merupakan limbah hasil pertanian setelah pemanenan kelapa sawit. Kandungan lignoselulosa berkisar 55-60 persen dari berat kering. TKKS memiliki serat dengan panjang antara 0,76-1,2 $\mathrm{mm}$ dengan diameter serat berkisar 15 sampai $114,34 \mathrm{~mm}$ serta memiliki bilangan Runkel 0,87-1,05 sehingga bisa dimanfaatkan untuk bahan baku pulp atau kertas [1]. Proses pemasakan TKKS menjadi pulp atau bubur kertas dikenal dengan proses pulping bisa menggunakan bahan pelarut organik seperti asam formiat dan asam asetat yang dikenal dengan nama proses formacell. Proses ini memiliki kelebihan yaitu menghasilkan rendemen yang tinggi, sisa $r$ lignin rendah, dan kekuatan yang baik [2-6]. Salah satu permasalahan pada proses pulping adalah warna yang dihasilkan masih gelap karena adanya sisa kromofor atau lignin yang tersisa di dalam pulp sehingga amemerlukan proses pemutihan atau bleaching. Salah satu bahan yang dapat digunakan untuk pemutih adalah asam peroksida. Beberapa peneliti menggunakan pemutih peroksida dengan media air yaitu Edahwati [7], 
Retnowati [8] dan Fuadi dan Sulistyo [9]. Pemutihan menggunakan peroksida dalam media asam asetat dilaporkan oleh Hidayati et al [10] pada kertas koran bekas dan Zuidar et al [11] dengan menggunakan konsentrasi peroksida sebesar $15 \%$ dalam waktu selama 3 jam pada pulp dari TKKS yang menghasilkan rendemen sebesar $84,85 \%$, selulosa $84,4 \%$, lignin 5,691 dan warna skor terhadap derajat putih yaitu 4,017 (putih kekuningan). Salah satu kelebihan penggunaan pemutih menggunakan peroksida dalam media asam asetat adalah cenderung tidak merusak selulosa dan bebas dari klor sehingga aman bagi lingkungan [12]. Faktor yang mempengaruhi proses pemutihan yaitu konsentrasi bahan pemutih [13], lama proses pemutihan [14], suhu, $\mathrm{pH}$, rasio antara bahan pemutih dengan pulp $[13,15,16]$. Proses pemutihan yang lama akan mempercepat reaksi pemutihan tetapi waktu yang panjang dapat mempengaruhui kerusakan serat. Tujuan penelitian ini adalah mengetahui pengaruh lama pemutihan terhadap karakteristik pulp TKKS yang dihasilkan pada proses pulping secara formacell.

\section{Metode Penelitian}

\section{Alat dan Bahan}

Bahan yang digunakan dalam penelitian adalah TKKS yang diperoleh dari PT Rejosari, asam asetat glasial, $\mathrm{H}_{2} \mathrm{SO}_{4}, \mathrm{KMNO}_{4}, \mathrm{KI}, \mathrm{Na}_{2} \mathrm{~S}_{2} \mathrm{O}_{3}, \mathrm{HCl}$, $\mathrm{H}_{2} \mathrm{SO}_{4}(72 \%)$, indikator amilum $0,2 \%$. Alat yang digunakan adalah digester pemasak pulp, alat penentu bilangan Permanganat, oven, dan alat-alat analisis lainnya.

\section{Pelaksanaan Penelitian}

Produksi pulp dilakukan dengan cara TKKS dibersihkan, dijemur sampai kering dan dilakukan pemisahan serat kemudian sebanyak diambil $1000 \mathrm{~g}$. Proses pemasakan pulp menggunakan metode formacell yaitu sebanyak 1000 g TKKS dimasukkan ke dalam reaktor erlenmeyer yang dilengkapi kondensor dan diberi larutan pemasak berupa asam formiat dan asetat. Proses pemasakan dilakukan dengan menggunakan larutan formacell yaitu asam formiat sebanyak $32,74 \%$ yang dilarutkan dengan media asam asetat dengan konsentrasi 96\% dengan rasio larutan pemasak:TKKS 15:1 dengan suhu pemasak $130{ }^{\circ} \mathrm{C}$ dengan waktu 1,71 jam [17]. Setelah itu dilakukan proses penyaringan, pencucian dan pengeringan. Pulp yang sudah dikeringkan kemudian dilakukan proses pemutihan menggunakan peroksida di dalam media asam asetat. Peroksida yang digunakan dengan sebanyaki $35 \%$ dari volume asam asetat. Pemutihan dilakukan pada suhu $80^{\circ} \mathrm{C}$ dengan waktu yaitu $0,5,1,1,5,2$ dan 2,5 jam dengan ulangan sebanyak 3 kali. Pengamatan dilakukan terhadap kadar selulosa [18], bilangan Permanganat (SNI 0494-89), rendemen dan skor berdasarkan uji skoring.

\section{Hasil Dan Pembahasan}

\section{Rendemen}

Hasil penelitian menunjukkan bahwa lama pemutihan dapat menyebabkan penurunan rendemen pulp sampai waktu 1,5 jam kemudian mengalami peningkatan kembali setelah 2 jam (Gambar 1). Rendemen yang dihasilkan berkisar 70 sampai $782 \%$. 


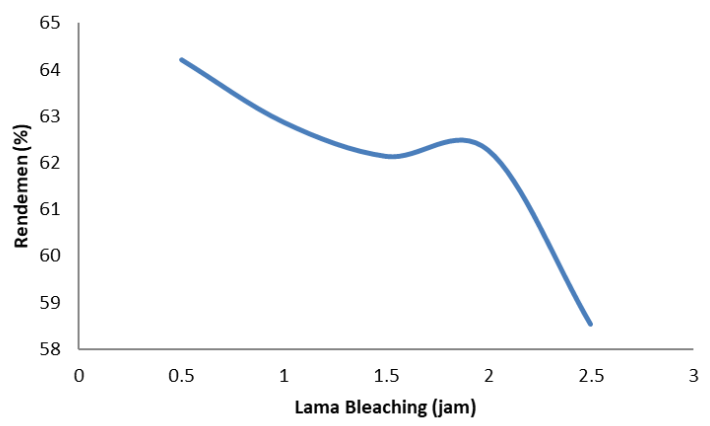

Gambar 1. Pengaruh lama waktu pemutihan terhadap rendemen pulp

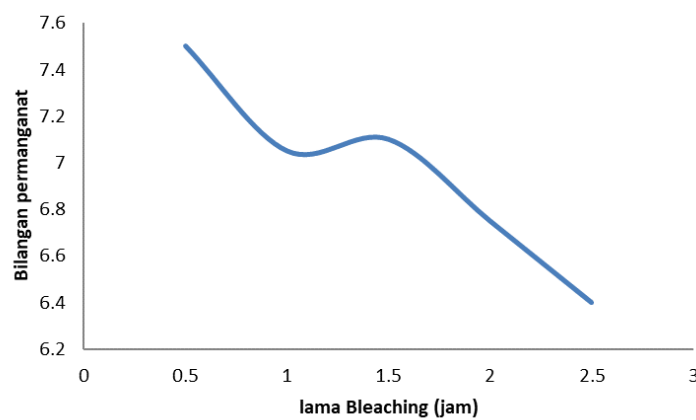

Gambar 3. Pengaruh lama waktu pemutihan terhadap bilangan permanganat pulp TKKS

Penurunan rendemen sampai lama waktu pemutihan 1,5 jam diduga karena terjadi penurunan kadar selulosa dan menurunnya kandungan lignin yang ditandai dengan penurunan bilangan Permanganat. Onggo [14] menyatakan bahwa waktu yang lama pada proses bleaching atau pemutihan dapat menyebabkan hemiselulosa, lignin dan pektin menjadi terlarut pada amedia pemutih sehingga menyebabkan rendemen menjadi berkurang.

\section{Kadar Selulosa}

Hasil penelitian menunjukkan bahwa peningkatan lama waktu pemutihan dapat amenurunkan kadar selulosa (Gambar 2). Kadar selulosa tertinggi terjadi pada lama pemutihan selama satu jam yaitu berkisar $57,2 \%$.

Asam peroksida merupakan media pemutih yang cukup selektif meskipun

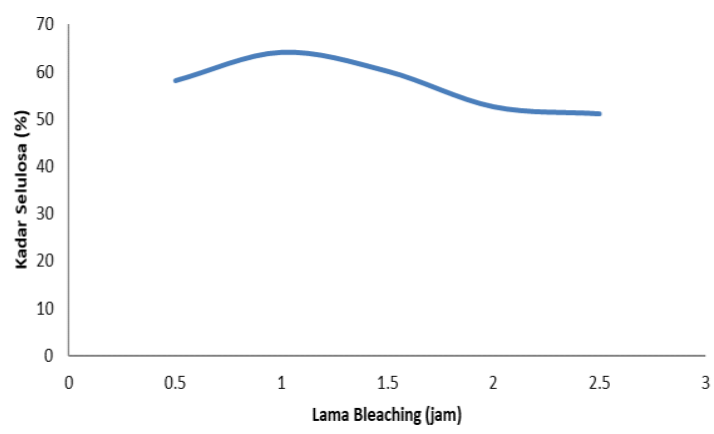

Gambar 2. Pengaruh lama waktu pemutihan terhadap kadar selulosa pulp TKKS

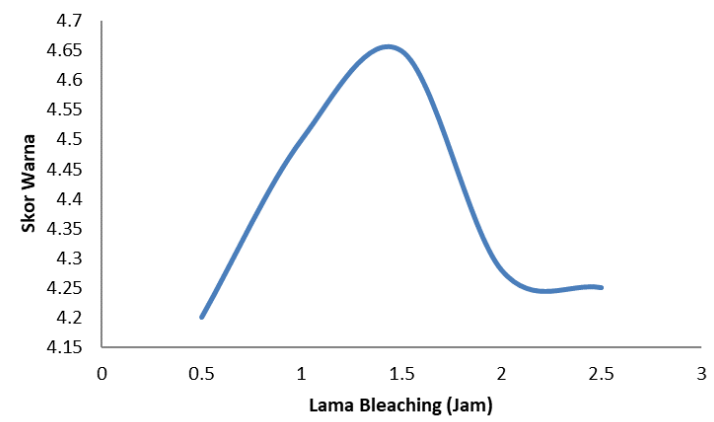

Gambar 4. Pengaruh lama waktu pemutihan terhadap skor warna pulp TKKS

bersifat oksidator taetapi hanya menguraikan selulosa seditkit dan hasil penguraiannya berupa gula sederhana yang mudah larut di dalam air [12]. Sehingga lama waktu pemutihan dapat menyebabkan peroksida yang aktif menjadi lebih banyak menguraikan selulosa sehingga mengakibatkan penurunan kadar selulosa.

\section{Bilangan permanganat}

Hasil penelitian menunjukkan bahwa peningkatan lama waktu pemutihan dapat menurunkan bilangan permanganat (Gambar 3). Nilai bilangan permanganat yang dihasilkan berkisar 6,6 sampai 7,2.

Pengujian Bilangan Permanganat digunakan dalam menentukan tingkat kematangan atau daya terputihkan dari suatu pulp kimia [19]. Semakin lama waktu pemutihan maka penetrasi bahan pemutih atau kemampuan 
mengoksidasi dari asam peroksida semakin tinggi sehingga menyebabkan lignin berkurang dan daya putih semakin tinggi. Hal ini ditandai dengan menurunnya nilai bilangan permanganat. Prinsip dasarnya adalah lignin akan mengkonsumsi kalium permanganat dengan kecepatan yang jauh lebih tinggi dari pada komponenkomponen karbohidrat di dalam pulp. Sehingga penggunaan kalium permanganat bisa digunakan untuk mengukur kandungan lignin didalam pulp. Kandungan lignin di dalam pulp semakin rendah dengan rendahnya bilangan kappa dan bilangan permanganat [9].

\section{Skor Terhadap Warna}

Peningkatan lama waktu pemutihan dapat meningkatkan skor terdapa nilai derajat putih (Gambar 4). Skor nilai berkisar pada satu (coklat), 2 (coklat kekuningan), 3 (kuning), 4 (putih kekuningan) dan 5 (putih). Warna tertinggi yaitu terjadi pada lama pemutihan selama 2 jam yaitu 4,5 (pembulatan ke putih).

Peningkatan waktu bleaching, dapat meningkatkan kecerahan pulp, hal ini diduga karena semakin lama waktu pemutihan maka proses oksidasi lignin akan berjalan lebih sempurna terutama dalam mengoksidasi kromofor. Hal ini menyebabkan lignin banyak yang terlepas, ditandai dengan menurunnya bilangan permanganat. Semakin lama waktu pemutihan dapat membuat larutan $\mathrm{H}_{2} \mathrm{O}_{2}$ semakin reaktif. $\mathrm{H}_{2} \mathrm{O}_{2}$ akan terurai menjadi ion $\mathrm{H}+$ dan $\mathrm{OOH}$ - dimana lon $\mathrm{OOH}$ - merupakan oksidator kuat yang berperan pada proses bleaching serat karena zat warna alam yang merupakan senyawa organik yang mempunyai ikatan rangkap yang dapat dioksidasi menjadi senyawa yang lebih sederhana atau menjadi senyawa yang mempunyai ikatan tunggal, sehingga dihasilkan serat yang lebih cerah [20]. Proses mekanismenya yaitu hidrogen peroksida mengoksidasi unit nonfenolik lignin melalui pelepasan satu elektron dan membentuk radikal kation yang kemudian terurai secara kimiawi. Lignin terdiri dari $90 \%$ unit nonfenolik. $\mathrm{H}_{2} \mathrm{O}_{2}$ memutus ikatan $\mathrm{C} \alpha-\mathrm{C} \beta$ molekul lignin dan mampu membuka cincin lignin dan reaksi lain dan mampu mengkatalis suatu oksidasi senyawa aromatik non-fenolik lignin membentuk radikal kation aril dan mengubah veratryl alkohol menjadi veratryl aldehyde [20, 21]. Sehingga semakin tinggi suhu dan semakin lama waktu perendaman maka larutan $\mathrm{H}_{2} \mathrm{O}_{2}$ sebagai oksidator dapat menyebabkan derajat putihnya makin tinggi [21].

\section{Kesimpulan}

Hasil penelitian menunjukkan bahwa perlakuan yang terbaik terjadi pada lama pemutihan selama 2 jam yang menghasilkan rendemen sebesar $79,6 \%$, selulosa $51,08 \%$, bilangan permanganat 6,8 dan skor terhadap warna adalah 4,5 (putih).

\section{Daftar Pustaka}

[1] Darnoko, P. Guritno, A. Sugiharto, and $S$. Sugesty, "Pembuatan Pulp ari tandan Kosong Sawit dengan Penambahan Surfaktan," J. Penelit. Kelapa Sawit, vol. 3, no. 1, pp. 75-87, 1995.

[2] A. Rodríguez and L. Jiménez, "Pulping with Organic Solvents Others than Alcohols," Afinidad, vol. 65 , no. 535, pp. 188-196, 2008.

[3] M. Paorjoozi, J. M. Rovsshandeh, and S. . Ardeh., "Bleachibility of Rice Straw Organosolv Pulp," 
Iran. Polym. J., vol. 13, no. 4, pp. 275-280, 2004.

[4] B. P. Lavarack, T. J. Rainey, K. L. Falzon, and G. E. Bullock, "A Preliminary Assessment Of Aqueous Ethanol Pulping Of Bagasse: The Ecopulp Process," Inter Sugar J., vol. 107, no. 1283, pp. 611-615, 2005.

[5] D. Yawalata and L. Paszner, "Anionic Effect In High Concentration Alcohol Organosolv Pulping," Holzforschung, vol. 58, no. 1, pp. 1-6, 2004.

[6] F. López, J. C. García, A. Pérez, M. M. García, M. J. Feria, and R. Tapias, "Leucaena diversifolia a new raw material for paper production by soda-ethanol pulping process," Chem. Eng. Res. Des. Inpress., 2004.

[7] L. Edahwati, "Proses Deinkin Kertas Koran Bekas Menggunakan Hidrogen Peroksida," J. Kim. dan Teknol., pp. 322-327, 2009.

[8] D. S. Retnowati, "Pemutihan Enceng Gondok Menggunakan H2O2 Dengan Katalisator Natrium Bikarbonat," Reaktor, vol. 12, no. 1, pp. 33-36, 2008.

[9] A. . Fuadi and H. Sulistya, "Pemutihan Pulping dengan Hidrogen Peroksida," Reaktor, vol. 12, no. 2, pp. 123-128, 2008.

[10] S. Hidayati, Z. A.S, and R. Widyastuti, "Pemutihan Kertas Koran Bekas Dengan Menggunakan Asam Peroksida Dalam Media Asam Asetat," Agrointek, vol. 12, no. 1, 2018.

[11] A. . Zuidar, S. Hidayati, and R. J. A. Pulungan, "Kajian Delignifikasi Pulp Formacell Dari Tandan Kosong Kelapa Sawit Menggunakan Hidrogen Peroksida (H2O2) Dalam Media
Asam Asetat," J. Teknol. Ind. dan Has. Pertan., vol. 19, no. 2, pp. 194-204, 2014.

[12] M. Sofian, "Kajian Pemutihan Pulp Acetosolve Campuran Ampas Tebu Dan Batang Pisang Menggunakan Hidrogen

Peroksida Dalam Media Asam Asetat," Universitas Lampung, 2011.

[13] J. E. G. Van Daam, Coir Processing Technologies: Improvement of Drying, Softening, Belaching and Dyeing Coir Fibre/Yarn and Printing Coir Floor Coverings. Netherlands: FAO and CFC, 2002.

[14] H. Onggo and T. Astuti., "Pengaruh Sodium Hidroksida dan Hidrogen Peroksida terhadap Rendemen dan Warna Pulp dari Serat Daun Nenas," . J. IImu dan Teknol. Kayu Trop., vol. 3, no. 1, pp. 37-43, 2005.

[15] R. Batubara, "Teknologi Bleaching Ramah Lingkungan," Universitas Sumatera Utara, 2006.

[16] A. Tutus, "Bleaching of Rice Straw Pulps with Hidrogen Peroxide," J. Biol. Sci., vol. 8, pp. 1327-1329, 2004.

[17] S. Hidayati, A. . Zuidar, and A. Fahreza., "Optimasi Produksi Pulp Formacell Dari Tandan Kosong Kelapa Sawit (TKKS) Dengan Metode Permukaan Respon," Reaktor, vol. 16, no. 4, pp. 161-171, 2016.

[18] R. Datta, "Acidogenic Fermentation of Linocellulose Acid Yield and Connvertion of Componens," Biotechnol. Bioeng, vol. 23, pp. 2167-2170, 1981.

[19] Dewan Standarisasi Indonesia, Cara Uji Bilangan Permanganat, Bilangan Kappa, dan Bilangan Khlor Pulp. Jakarta: Departemen 
Sri Hidayati dkk.: Karakteristik Pulp Hasil Pemutihan Dari Tandan Kosong Kelapa Sawit Hasil Pemasakan Yang Menggunakan Limbah Lindi Hitam Siklus Ketiga

Perindustrian, 1989

[20] Jayanudin, "Pemutihan Daun Nanas Menggunakan Hidrogen Peroksida," J. Rekayasa Proses, vol. 3, no. 1, pp. 10-14, 2009.
[21] Suparjo, "Degradasi Komponen Lignoselulosa oleh Kapang Pelapuk Putih," jajo66. wordpress.com, 2008. 